\title{
El arte visual como herramienta de investigación para analizar la imaginación de los niños.
}

\author{
Visual art as a research tool for analyzing the imagination of \\ children.
}

\section{Michela Fabbrocino}

Universidad de Granada (España)

michela.fabbrocino@gmail.com
Recibido 25/09/2020 Revisado 18/10/2020

Aceptado 18/10/2020 Publicado 31/10/2020

\section{Resumen:}

Las tecnologías basadas en video e imagen han cambiado las formas tradicionales de realizar ciertas tareas y, aún más, la forma en que adultos y niños descifran y entienden el mundo. El método de comunicación ofrecido por el sistema de medios expone al espectador a información repetitiva y fugaz que promueve una actitud acrítica y lo priva de la posibilidad de interactuar. El problema de un aprendizaje que pasa por un consumo incontrolado de tecnologías de audio y video es la ausencia de un puente que conecte los datos adquiridos con la capacidad de codificar información.

En sí mismos, los medios no afectan negativamente la creatividad de los niños. El problema es su mal uso. En el curso de mi investigación, observé que el consumo incontrolado de televisión tiende a limitar las capacidades creativas vinculadas a la imaginación y la codificación cerebral, ya que el niño no logra asimilar el contenido multimedia de manera autónoma y adecuada. Si la imagen mental proviene de una imagen audiovisual externa, si no se procesa o construye de manera personal, para el niño no existe un esquema claro de conocimiento, sino un conjunto de elementos sin un orden lógico. (Arboleda Estudillo, 2013).

Sugerencias para citar este artículo,

Fabbrocino, Michela, (2020). El arte visual como herramienta de investigación para analizar la imaginación de los niños. Tercio Creciente (Monográfico extraordinario II), págs. 155-173, https://dx.doi.org/10.17561/rtc.extra2.5790

FABBROCINO, MICHELA. El arte visual como herramienta de investigación para analizar la imaginación de los niños. Tercio Creciente (Monográfico extraordinario II) octubre 2020 pp. 155-173, https://dx.doi.org/10.17561/rtc.extra2.5790 


\section{Abstract:}

Video and image-based technologies have changed the traditional ways of performing certain tasks and, even more, the way adults and children decipher and understand the world. The communication method offered by the media system exposes the viewer to repetitive and fleeting information that promotes an uncritical attitude and deprives them of the possibility of interacting. The problem of learning that goes through uncontrolled consumption of audio and video technologies is the absence of a bridge that connects the acquired data with the ability to encode information.

By themselves, the media does not adversely affect children's creativity. The problem is its misuse. In the course of my research, I observed that uncontrolled television consumption tends to limit creative capacities linked to imagination and brain coding, since the child does not manage to assimilate multimedia content in an autonomous and adequate way. If the mental image comes from an external audiovisual image, if it is not processed or constructed in a personal way, for the child there is no clear scheme of knowledge, but rather a set of elements without a logical order. (Arboleda Estudillo, 2013).

Palabras Clave: Educación, investigación educativa, artes visuales, medios de comunicación, imaginación

Key words: Education, educative research, visuall arts, mass media, imagination

Sugerencias para citar este artículo,

Fabbrocino, Michela, (2020). El arte visual como herramienta de investigación para analizar la imaginación de los niños. Tercio Creciente (Monográfico extraordinario II), págs. 155-173, https://dx.doi.org/10.17561/rtc.extra2.5790

FABBROCINO, MICHELA. El arte visual como herramienta de investigación para analizar la imaginación de los niños. Tercio Creciente (Monográfico extraordinario II) octubre 2020 pp. 155-173, https://dx.doi.org/10.17561/rtc.extra2.5790 


\section{El juego como espacio de libertad e imaginación}

Cuando un niño juega, a menudo, se imagina que es otra persona: proyecta otro yo en su imaginación, a veces igual a él con diferentes características, otras veces un personaje conocido en su propia realidad y redefinido de acuerdo con las necesidades de ese momento; adquiere temporalmente rasgos o actitudes, simula acciones y discursos. En los juegos de ficción, el niño refleja lo que ve y oye cuando mira a los adultos, pero no se limita a reproducir las experiencias que ha vivido: las reelabora creativamente, combinándolas entre sí y construyendo una nueva realidad de acuerdo con sus gustos y necesidades. Es en el momento del juego que el niño usa su imaginación a voluntad, esa imaginación que, como sabemos por Vygotskij, depende de la realidad y de las experiencias anteriores: cuanto más rica sea la experiencia humana, más material estará disponible para la imaginación. (Vygotskij, 1986, págs. 19-20). Al mismo tiempo, observa Perner, el niño mantiene el control de la situación para no caer en el error de confundir lo real con lo simulado (Perner, 1994, p. 74).

El momento del juego representa un papel fundamental en la construcción del "yo" infantil y en la consolidación de la autoestima. Como se demostró en numerosas investigaciones sobre el juego en la educación primaria, funciona como una estrategia de liberación y constituye una plataforma formidable para la creatividad, así como para el aprendizaje. Bruner (1984, p. 219) subraya esto: "Jugar para el niño y para el adulto [...] es una forma de usar la mente, una actitud sobre cómo usar la mente. Es un momento para probar situaciones, un invernadero en el que combinar pensamiento, lenguaje e imaginación". El juego es también el entorno natural de aprendizaje del niño porque crea un área de "desarrollo próximo" (Vygotskij , 1979, p. 156) donde se mueve más allá de la edad media y el comportamiento habitual ${ }^{1}$. Los estudios más recientes confirman que en su actividad recreativa espontánea con otros niños, el individuo se siente seguro y dispuesto a crear y experimentar hasta el límite máximo de sus habilidades, afirma su autocontrol y logra objetivos que asimila fácilmente porque respetan sus posibilidades reales para llevar a cabo una actividad específica y así obtener satisfacción personal (Vandenplas - Holper, 1982, p. 5). El juego se define en términos de "prueba libre de riesgos" (Lotman, 1973, p. 105): permite al jugador (y al grupo) posicionarse en situaciones que no pertenecen a la realidad, pero son similares, y por esta razón es una herramienta extremadamente efectiva para aprender varios tipos de comportamiento y para enfrentar diferentes situaciones de la vida.

Su carácter de casi-realidad confiere libertad y audacia al jugador, que puede ir más allá de lo conocido y aceptar el riesgo de fracaso porque sabe que esto no tendrá consecuencias frustrantes, como recuerda Bruner (1984, p. 212). De ahí el valor terapéutico y la liberación

\footnotetext{
1 La "zona de desarrollo proximal" se activa cuando, en la interacción entre un sujeto más competente (el educador) y el sujeto que tiene una desventaja intelectual (el niño), el primero saca en el segundo cualidades intelectuales que todavía no ocurrían y que no podían ocurrir de forma aislada.
} 
ISSN: 2340-9096

https://dx.doi.org/10.17561/rtc.extra2.5790

implícita que implica el juego en tantas ocasiones: no es casualidad que los más tímidos a menudo elijan el papel de niños terribles (Tappolet, 1982, p. 6).
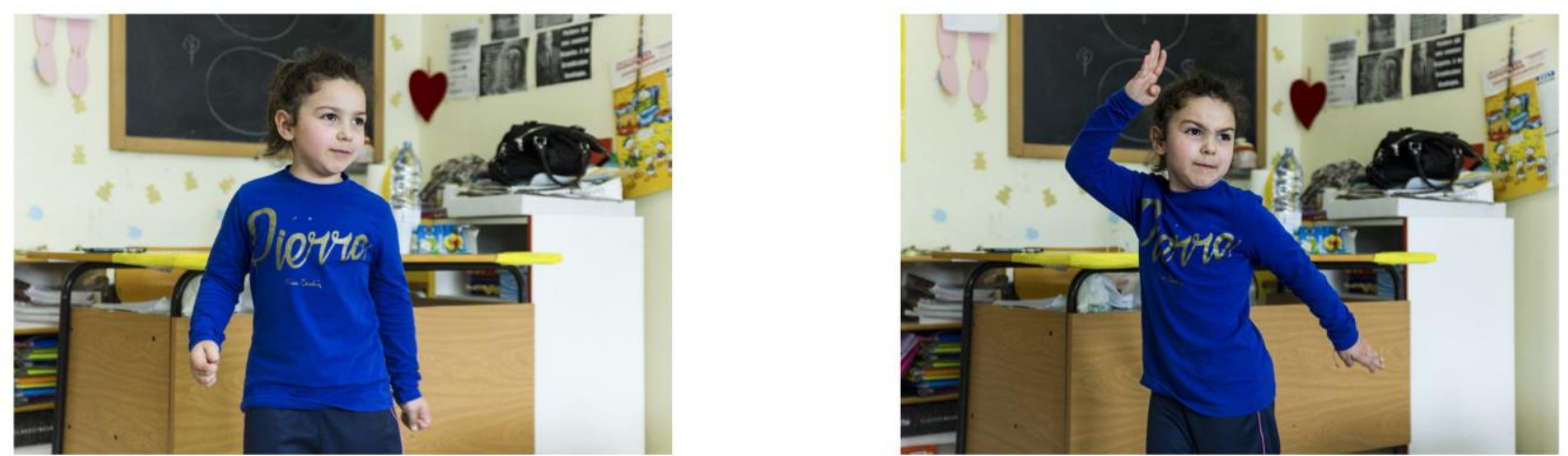

1. Fotoensayo. Autora (2017). Consta de dos fotografías que representan a una niña de cinco años que se transforma en un personaje.

El juego libre elimina lo que Wallach y Kogan llaman "obstáculos motivacionales", comportamientos preexistentes que inhiben la capacidad del individuo de desplegar completamente su creatividad e inteligencia: por ejemplo, la paralizante preocupación por la opinión sobre el desempeño personal, la tendencia de cometer más errores si está sujeto a juicios de valor o a la mirada de los demás. "La conciencia creativa tiende a ocurrir cuando el individuo en un 'modo lúdico' fomenta las posibilidades, sin preocuparse por el éxito para sí mismo o el fracaso personal de cómo se ve la imagen de sí mismo en los ojos de los demás" (Wallach Kogan, 1983, p. 84). El juego es, por lo tanto, el reino de la libertad, el entorno de descubrimiento e investigación, el espacio desde el cual el juicio, los modelos estéticos preconcebidos y las rigideces programáticas quedan excluidas. El psicólogo Winnicott cree que solo en el juego puede manifestarse la capacidad creativa ("en él, y quizás solo en él, el niño o el adulto es libre de ser creador") y subraya la importancia de la creatividad en la vida humana: "[ .... el individuo descubre a su persona solo cuando demuestra ser un creador "(Winnicott, 1982, pp. 79-80). 
ISSN: 2340-9096

https://dx.doi.org/10.17561/rtc.extra2.5790

\section{El juego en la cultura visual de hoy}

Desde la infancia, la vida del niño está marcada por los ritmos de una rutina (entrada, comidas, cuidado del cuerpo, descanso) que proporciona una integración equilibrada de los momentos de cuidado, relación y aprendizaje y que se ofrece a los niños como "base segura" sobre la cual injertar nuevas experiencias, de acuerdo con las pautas de los programas ministeriales de 20122. Esta rutina bien reconocida por los niños los hace plenamente conscientes de que el momento de juego es único e irrepetible durante todo el día y es en ese momento que pueden dedicarse a su imaginación, donde el juego es gratuito y no guiado por educadores. Y es en esta fase donde se desarrolla el juego de roles, la primera forma de teatralidad de los niños, en la que demuestran su disposición natural para la imitación y la ritualización y, progresando en el juego dramático y en sus múltiples formas de expresión y creatividad, huyen de una dimensión pública y de entretenimiento e investigan a fondo sus necesidades expresivas al rechazar las diversas intenciones de manipulación de los adultos (Tejerina Lobo, 2005, p. 9.).

Los niños se organizan de manera independiente, asignan roles y comienzan a jugar. Este es el momento en que un niño característicamente más fuerte elige en qué personaje transformarse y qué otros personificar.

Pero, ¿cuál es el juego que el niño prefiere hoy? ¿Cuáles son los roles hacia los cuales se orienta más a menudo?

En la investigación que la autora realizó en 2017 en San Gennaro Vesuviano con una clase de niños de cinco años, el autor ha documentado que alrededor del 85\% de ellos siempre y solo eligen el mismo personaje, extraído del mundo de los dibujos animados favoritos; como conoce muy bien al personaje en cuestión, sabe perfectamente cómo responder al juego dramático $\mathrm{y}$, sin establecer reglas precisas, emula sus acciones al proponer un episodio específico de la serie. De hecho, los niños siempre se han inspirado en la realidad para recrear un papel que jugar, como dice Vygotskij; pero si en el pasado los personajes de referencia eran los de la madre, el padre o los tíos, hoy los niños parecen haber olvidado que podían recurrir a su familia y a la realidad concreta, y las figuras dominantes ahora son casi exclusivamente los protagonistas de la serie de televisión y videojuegos, como es inevitable dada la fuerte impronta visual y mediática de la cultura en la que los niños están inmersos. 


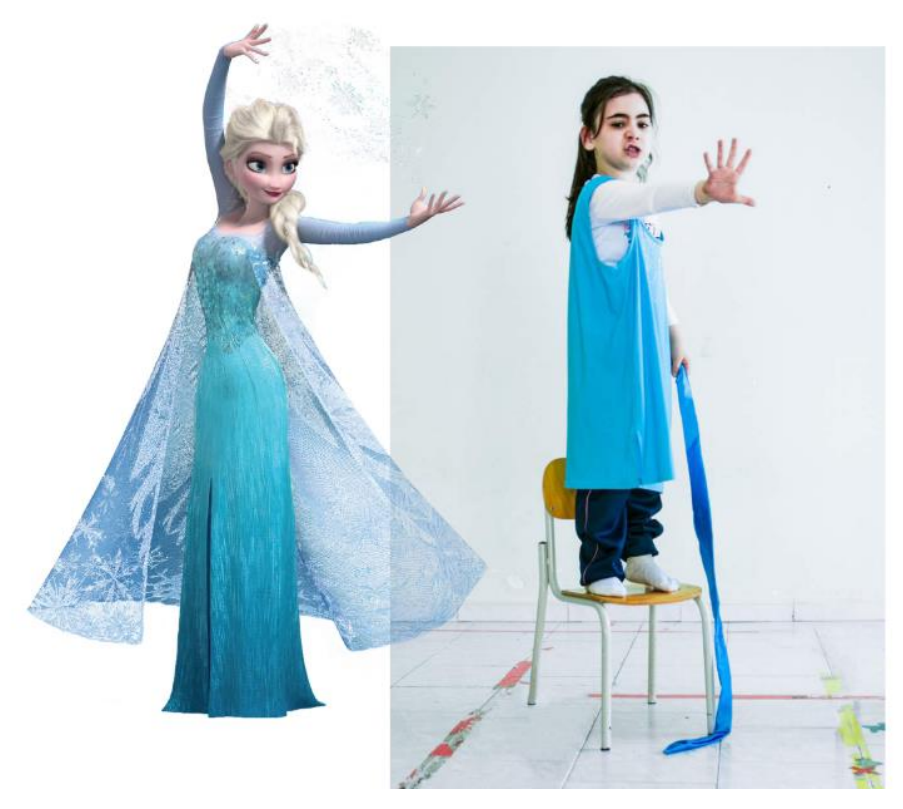

2. Par fotográfico. Autora. (2017). Compuesta por una fotografía que representa a una niña de cinco años que se transforma en el personaje de Elsa, la protagonista de la película animada "Frozen" y una imagen de la caricatura antes mencionada.

¿Pero a qué nos referimos cuando hablamos de "cultura visual"? Según el vocabulario de Treccani, el término "cultura" puede definirse como el conjunto de conocimientos adquiridos a través del estudio y la experiencia, que permiten a un individuo desarrollar "conciencia de sí mismo y del mundo", pero también como conjunto de valores, símbolos, modelos de comportamiento propios de un grupo social. De hecho, los últimos treinta años han visto una renovación en la definición del concepto de "cultura", particularmente en el campo científico. Autores como Aznar, Batista y González (2000, p. 69) han redefinido el significado del término, dándole un significado más amplio de un conjunto de datos: "cultura [...] se refiere a la serie de recuerdos que testifican y canalizan el curso de supervivencia del grupo social". Otros (Steinberg - Kincheloe, 2000, p. 133) entienden por "cultura" el conjunto de ideas que las personas tienen de sí mismas y de la sociedad en la que viven". Después de este cambio de perspectiva, que se ha definido como un "punto de inflexión cultural", la cultura se ha convertido en el terreno privilegiado sobre el que se mueven los científicos sociales para comprender cuestiones como los procesos sociales, las identidades sociales y el cambio social.

Los nuevos estudios culturales, desarrollados en diferentes contextos sociales, teóricos e históricos, han adoptado una perspectiva multidisciplinaria también sobre la educación infantil, centrándose en la dimensión cultural de las imágenes y el contenido transmitido por los medios y adoptando nuevos temas: la imagen que los niños tienen de sí mismos, los signos presentes en 
las imágenes visuales que más les interesan, lo que aprenden de esos signos y señales, su forma de retratar el poder social ejercido por los adultos, la idea que los maestros tienen de la infancia, cómo podemos hacer que los niños nos den información sobre el impacto de la cultura popular en su visión del mundo, etc. El desarrollo de estas ideas ha abierto nuevas vías para la investigación y los caminos que se pueden cubrir en el campo de la educación artística (Steinberg - Kincheloe, 2000, en Chacón Gordillo, 2011, pp. 29-31).

Siempre que trabajamos con una narrativa relacionada con el consumo audiovisual de la infancia, por un lado vamos en continuidad con un proceso educativo iniciado en casa frente a una pantalla, reconociendo así que los niños ya han vivido y están aprendiendo en el campo cada vez más importante de la educación no formal; por otro lado, tenemos la oportunidad de explotar, a través de la experiencia docente, las herramientas que la cultura visual contemporánea pone a nuestra disposición para desmitificar, para humanizar a los héroes de la televisión; es decir, podemos guiar a los niños para que transfieran sus rasgos positivos a las personas y situaciones que enfrentan en la vida cotidiana, de acuerdo con un principio fundamental de cada camino educativo: "si aprendes a leer, tienes el control; si solo ves, otros lo tienen "(Acaso, 2009, p. 90).

\section{Niños y televisión}

Las tecnologías basadas en video e imagen han cambiado las formas tradicionales de realizar ciertas actividades y, aún más, la forma en que adultos y niños descifran y entienden el mundo. El método de comunicación que ofrece la televisión expone al espectador a información repetitiva y fugaz que promueve una actitud acrítica y elimina la posibilidad de interactuar. El problema del aprendizaje que pasa por el consumo incontrolado de tecnologías de audio y video es la ausencia de un puente que conecte los datos adquiridos con la capacidad de codificar información.

Las repercusiones son fuertes también en el proceso de debilitamiento de la infancia. Hoy en día los padres ya no controlan las experiencias culturales de sus hijos, expuestos diariamente a una miríada de imágenes para ser consumidas sin ningún control por parte de las familias. Los programas de televisión, el mundo de las imágenes, las películas animadas (presentes en la televisión pública, en plataformas pagas, en DVD, a través de descargas de Internet, etc.) y los videojuegos representan un área exclusiva del niño en el que se desarrolla. 
ISSN: 2340-9096

https://dx.doi.org/10.17561/rtc.extra2.5790

Una transmisión continua de valores hacia los pequeños. En el estado actual, a los niños y niñas se les da una visión particular del mundo que está lejos de la de hace años, cuando la importancia que la sociedad daba a la protección de los niños era mayor y había pocas experiencias culturales que no se compartían, controlados y observados por los padres (Buckingham, 2005, p. 47).
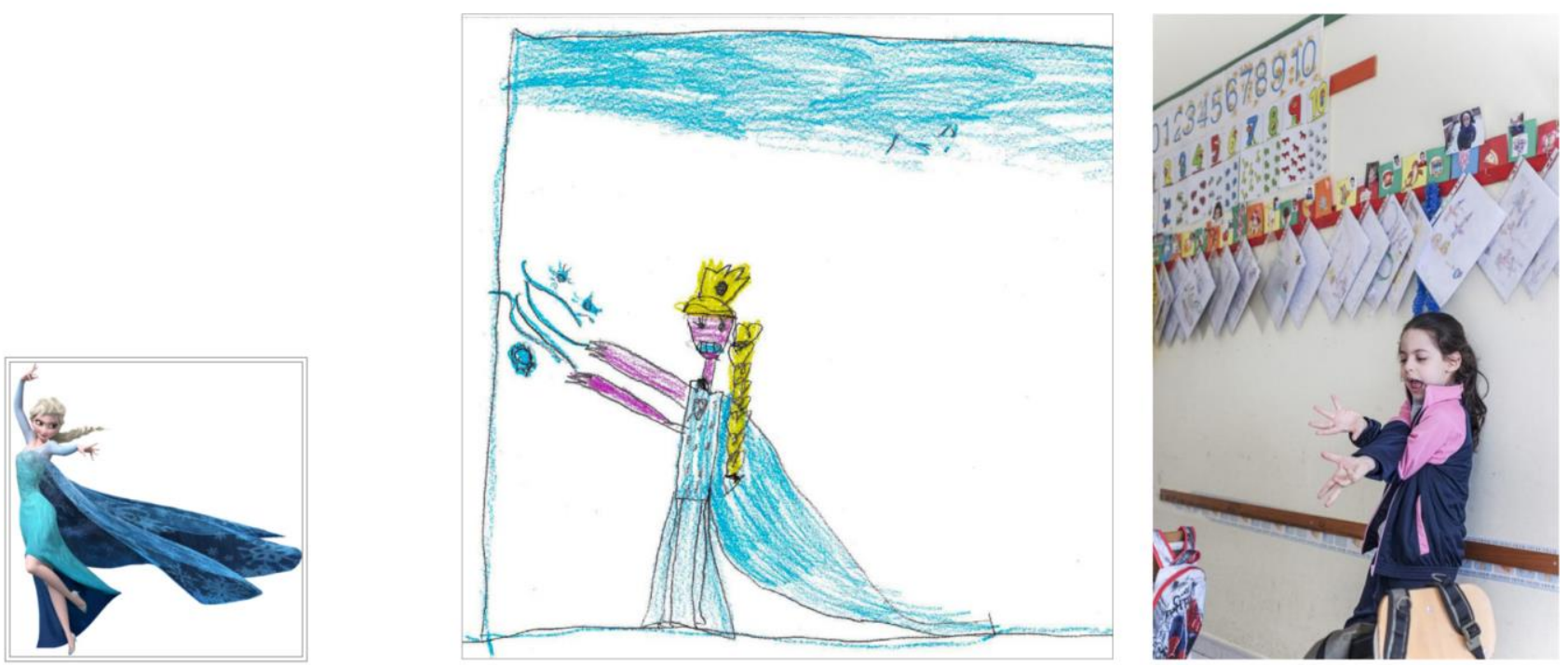

3. Par fotográfico. Autora. (2017). Compuesta por una fotografía que representa a una niña de cinco años que se transforma en el personaje de Elsa, la protagonista de la película animada "Frozen", una imagen de la caricatura antes mencionada y un dibujo de la niña dedicado a Elsa. 


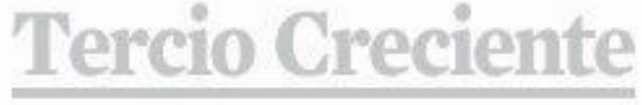

ISSN: 2340-9096

https://dx.doi.org/10.17561/rtc.extra2.5790

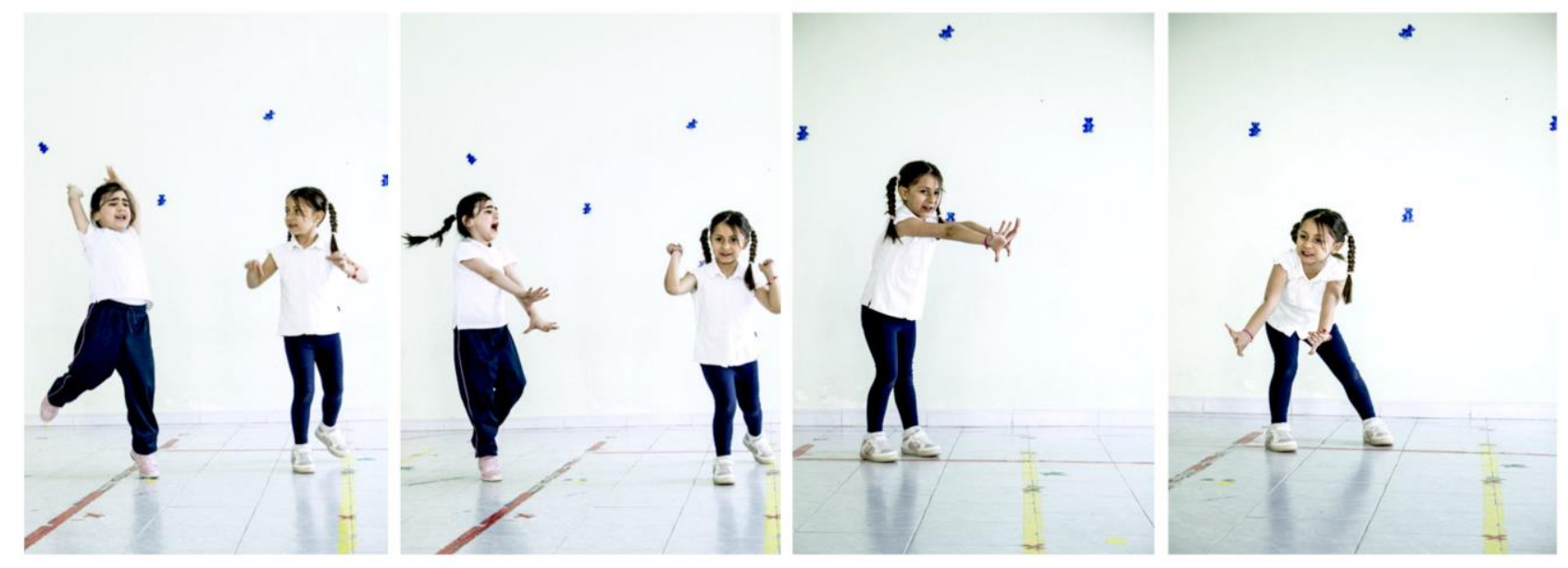

4. Fotoensayo. Autora. (2017). Compuesta por cuatro fotografías que representan a dos niñas de cinco años que se transforman

Al revisar la mayoría de los estudios sobre tecnologías de televisión y video, es difícil encontrar opiniones favorables sobre el papel que tiene la infancia como audiencia. Los expertos coinciden en que el consumo de televisión puede tener efectos negativos en el desarrollo mental y físico de los niños, ya que conduce a la adopción de métodos de aprendizaje pasivo y conductas del lenguaje y conductas consideradas inadecuadas. Este punto de vista, sin embargo, devalúa completamente el medio audiovisual, que ofrece numerosas oportunidades tanto como herramienta para la educación como en otras áreas; por ejemplo, en los hospitales de los Estados Unidos, los dibujos animados se usan como terapia porque se ha demostrado que ayudan a muchos pacientes a relajar su estado nervioso y hacer que su estadía sea más llevadera (Carpenter, 2003, pp. 24-26).

En sí misma, la televisión no afecta negativamente la creatividad de los niños. El problema es su mal uso. Durante la investigación, el autor observó que el consumo incontrolado de televisión tiende a limitar las habilidades creativas relacionadas con la imaginación y la codificación del cerebro, ya que el niño no logra asimilar el contenido multimedia de manera independiente y adecuada.

Según Edwards (2006), cuyos estudios se han centrado en analizar las funciones de los hemisferios cerebrales en relación con la expresión artística, estos actos prefieren una lateralización pronunciada de las funciones del pensamiento. En otras palabras, las funciones de pensamiento concretas se consolidan en un solo hemisferio, subestimando y infrautilizando al otro. En general, la lateralización tiende a favorecer el hemisferio izquierdo, relacionado con el pensamiento lógico-verbal, el cálculo, la expresión y la conversión de información en palabras y conceptos. Aplicando estas adquisiciones a la teoría del pensamiento creativo, se deduce que el consumo incontrolado de televisión favorece el pensamiento vertical mucho más que el pensamiento lateral y divergente. 
El origen de los esquemas de conocimiento del niño (y, por lo tanto, de los esquemas gráfico-pictóricos) reside:

en el uso de imágenes mentales como unidad de operación;

en el esfuerzo de la mente por imaginarlas, un esfuerzo que nos obliga a identificar una estructura en forma de modelo o esquema, y no una simple yuxtaposición de elementos independientes (Cabanellas, 1975, p. 92).

Sin embargo, si la imagen mental proviene de una imagen audiovisual externa, si no se procesa o construye de manera personal, no hay un patrón claro de conocimiento para el niño, sino un conjunto de elementos sin un orden lógico. La consecuencia de esto es la aparición en los dibujos de elementos ilógicos, porque no están internalizados, lo que lleva a los niños a desanimarse durante la actividad o les hace copiar de otras fuentes, por ejemplo, de los dibujos de sus compañeros o de libros ilustrados (Arboleda Estudillo, 2013, p. 238).

A partir de la inclusión en los dibujos de elementos gráficos y códigos espaciales de naturaleza externa y estereotipada, en particular de las tecnologías de video y multimedia, algunos expertos distinguen dos tipos de procesos mentales por los cuales se asumen estos elementos. El primero actúa como una fase de procesamiento activa, durante la cual el niño produce conocimiento a partir de su propia estructuración de datos de información; en otras palabras, las estructuras de conocimiento se producen dinámicamente y con participación personal. Por el contrario, el segundo proceso actúa como una fase pasiva de almacenamiento de información, ya que, en general, da lugar a estructuras de conocimiento sin tener conocimiento; en este modo, se toman e internalizan datos estereotipados que se aplican a los conceptos prototipo de conocimiento, incluso sin una comprensión completa por parte del menor. En general, el proceso activo está vinculado a un consumo positivo adecuado de tecnologías de televisión y video, y el proceso pasivo al consumo negativo e incontrolado que se hace de él. El entorno en el que el niño vive y realiza sus dibujos está estrechamente relacionado con el proceso que gira en torno al dibujo infantil. El contexto social es un aspecto a tener en cuenta especialmente si hay cambios en la representación y la expresión artística. Dentro de esto, el niño participa en un proceso de extracción de información per se, pero también es bombardeado con mensajes directos e indirectos, principalmente audiovisuales, que contienen todo tipo de valores (Arboleda Estudillo, 2013, pp. 236-239). 
ISSN: 2340-9096

https://dx.doi.org/10.17561/rtc.extra2.5790

\section{Patrones de conocimiento y estereotipos en la primera infancia: la investigación de Rebeca Arboleda}

Ahora me gustaría analizar el estudio realizado por Rebeca Arboleda sobre el uso de la televisión por los niños en edad preescolar, porque su análisis de los dibujos revela información valiosa sobre los patrones del conocimiento de la infancia y sobre la adopción de elementos externos (estereotipos y símbolos) asimilados por el contexto multimedia y sin procesar. El proyecto de investigación, que duró unas pocas semanas, involucró a estudiantes de varias escuelas en Granada en actividades de dibujo gratis, dibujo propuesto después de leer una historia, dibujo propuesto inmediatamente después de ver una caricatura y luego dos días después la visión. El objetivo era profundizar la capacidad del niño para procesar diversos tipos de información (personal, leída y escuchada, audiovisual), también con el apoyo de pruebas sobre creatividad y consumo de televisión.
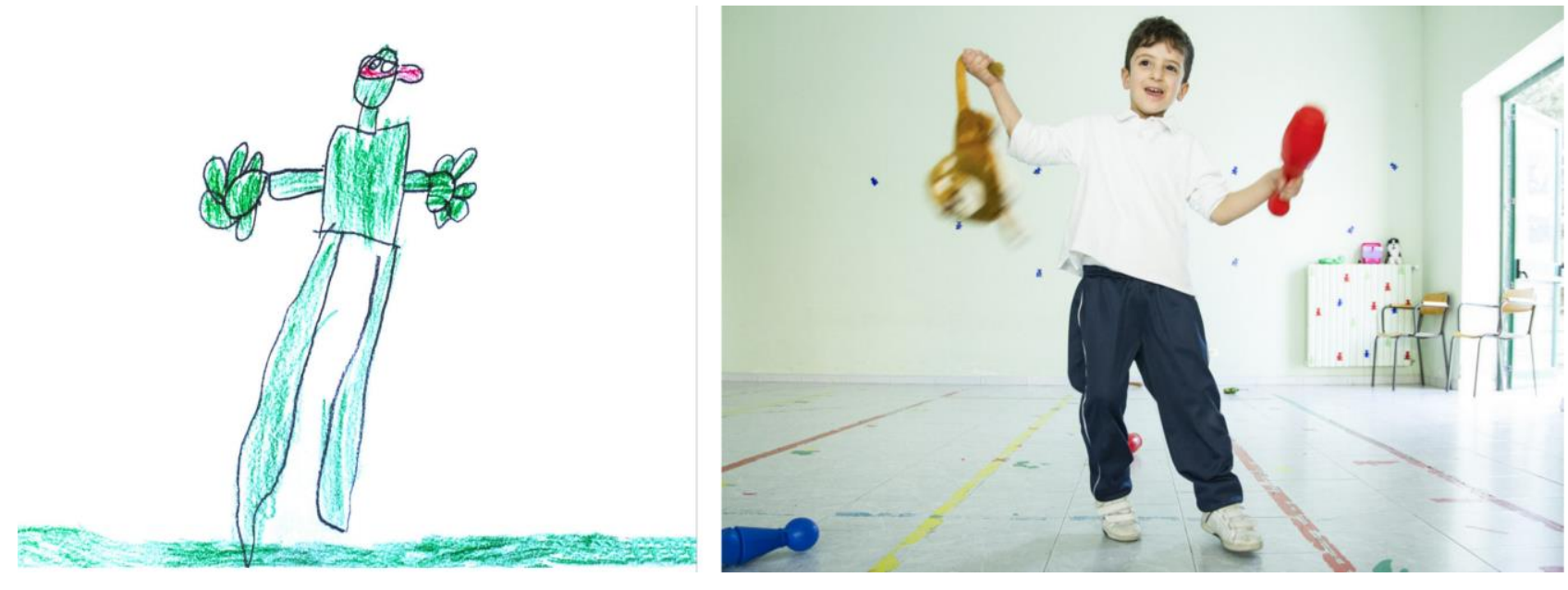

5. Par fotográfico. Autora. (2017). Consiste en una fotografía que representa a un niño de cinco años que se transforma en el personaje de dibujos animados "Tortuga Ninja" y un dibujo del niño que representa la caricatura antes mencionada.

En primer lugar, los dibujos se clasificaron en varios grupos según su mayor o menor creatividad, gracias a un análisis visual comparativo basado en la originalidad de la técnica y el tema; al observar los dibujos realizados inmediatamente después de ver los dibujos animados y los producidos después de dos días, se observó que un mayor intervalo de tiempo permite a los 
niños asimilar los contenidos audiovisuales y traducirlos a su propio lenguaje artístico. También hubo una fuerte asociación entre los diseños menos creativos y el consumo inapropiado de televisión, que, según los datos obtenidos de las pruebas, afecta al 60,6\% de los participantes, y se dedujo que este tipo de consumo bloquea la capacidad del niño para procesar correctamente la información, adaptarla a sus recursos gráficos y, por lo tanto, producir resultados originales, subjetivos y consistentes.

Por otro lado, la investigadora sugiere las pautas para un uso responsable de la televisión, que la transforma en una herramienta de información y aprendizaje: no dejar al niño solo frente a la pantalla y, sobre todo, a programas no diseñados para su edad; exponerlo a transmisiones por un corto tiempo y con pausas, para permitirle procesar información activamente; no lo prive de la oportunidad de comentar, preguntar, criticar; combine el consumo de televisión con otras actividades que requieren imaginación, como leer y moverse al aire libre. (Arboleda Estudillo, 2013, pp. 310-311).

\section{Dibujo y fotografía al servicio de la investigación: bases teóricas.}

Las investigaciones realizadas en las escuelas de Granada y San Gennaro Vesuviano se basan en los principios de la Investigación Educativa basada en Artes Visuales, es decir, aplican una metodología que utiliza dibujos e imágenes fotográficas para investigar temas relacionados con la enseñanza y el aprendizaje (Hamilton 2006 ).

La investigación en artes visuales es aquella que entiende las imágenes como un modelo de visualización. En primer lugar, las usa por sus cualidades estéticas, ya que una modalidad de investigación artística debe contener, usar y manifestar cualidades estéticas durante todo el proceso o en una parte sustancial del mismo. En segundo lugar, las considera como un medio de representación y comprensión capaz de influir decisivamente en el aspecto de las investigaciones y sugerir nuevos enfoques; la tarea fundamental de la investigación artística, de hecho, es proporcionar información y aumentar nuestra imaginación. La creación de productos visuales y la búsqueda de nuevas formas de imaginar representan la única forma de superar los límites de nuestras creaciones, ir más allá de nuestra forma actual de concebir lo posible, aumentando así la posibilidad de que la investigación futura sea más profunda y eficaz en todos los campos.

Weber y Mitchell (Weber - Mitchell, 2004) identifican varios aspectos clave de la investigación basada en el arte: representa lo que es difícil de expresar con palabras; puede comunicarse de manera integral y simultánea el todo y sus partes; convierte lo personal en social y lo privado en público. 
Como herramienta de investigación, el diseño fue elegido primero, como un espejo comunicativo del papel elegido por el niño. Según Maestre (2010), el dibujo es una forma de comunicación y expresión presente en las sociedades humanas desde la antigüedad, al igual que la necesidad de externalizar y comunicar los sentimientos es vital desde el comienzo de la vida (Callejo, 2014). Si un individuo no puede expresar libremente sus sentimientos verbalmente o por escrito, ya sea porque no se le permite hacerlo, o porque no tiene un desarrollo motor adecuado, o porque no tiene el coraje para hacerlo, el dibujo se convierte en la única manera de satisfacer una necesidad fundamental para él. Delval (1995) subraya la estrecha correlación entre el dibujo y el lenguaje escrito: el niño aún no lo domina y, por lo tanto, el dibujo es tan importante para él como forma de expresión; por otro lado, el dibujo requiere un dominio motor y un desarrollo muscular muy similar al que tendrá el niño cuando comience a delinear las letras, por lo que el dibujo también representa un gran "gimnasio" para el desarrollo de habilidades psicomotorias correctas de las articulaciones y de las extremidades y para la mejora de la coordinación visual-manual.

El dibujo también contribuye a muchos aspectos centrales del camino evolutivo de cada individuo en sus primeros años de vida: no solo entrena la competencia artístico-visual, la capacidad de establecer relaciones entre los diversos elementos que fluirán en el "dibujo del proyecto", las habilidades lo cual será fundamental para la lectura y escritura correctas, pero también le permite adquirir un código artístico, un idioma para el que no se deben enseñar reglas básicas, a diferencia de lo que sucede con los idiomas orales y escritos (Sáinz, 2003). Por lo tanto, el dibujo funciona como entrenamiento de la personalidad: las representaciones de los niños son los "borradores" de sus manifestaciones futuras.

Siguiendo la teoría de Vygotsky, el dibujo no es más que un lenguaje gráfico que parte del lenguaje verbal, lo integra y se enriquece a su vez. Podemos observar cómo el niño, mientras progresa en su desarrollo gráfico, lo integra con explicaciones verbales o, viceversa, produce explicaciones verbales que luego se completan con un dibujo.

Según Piaget, la función simbólica (o semiótica) se adquiere alrededor del año y medio o dos años. Esta función, que es exclusiva del ser humano, se define como la capacidad de representar un significado (un objeto, un evento, etc.) a través de un significante (destinado a representar algo). Durante el período sensoriomotor, el individuo ya tiene la capacidad de interpretar índices y señales, que otros llaman representación; sin embargo, continúa Piaget, no es correcto usar esta denominación hasta que se establezca la diferenciación entre significantes y significados; por ejemplo, el niño que reconoce un sonajero a través del tacto o el sonido no constituye una representación; lo sería si el niño reconociera el sonajero sin estar presente. 
En la fase que precede a la adquisición de la función simbólica, el papel de la imitación es fundamental (UNED, 2015, p.17): los niños pueden representar ciertos objetos recurriendo en gran medida a los aspectos motores, es decir, imitando significados a través los movimientos del propio cuerpo.

La investigación recurrió al análisis mediante el uso de la fotografía, partiendo del supuesto de que "las imágenes fotográficas son un buen método de observación y son muy útiles en muchas disciplinas y en muchas aplicaciones porque son capaces de recopilar y mostrar la información de manera confiable para estudiarla y analizarla luego" (Roldán, 2012, p. 78). En particular, son el punto de partida ideal para analizar e interpretar procesos y actividades educativas y artísticas, por varias razones: en primer lugar, porque constituyen una herramienta válida para representar el conocimiento; segundo, porque son capaces de organizar y demostrar ideas, hipótesis y teorías de manera equivalente a otras formas de conocimiento; y tercero, porque proporcionan información estética sobre tales objetos, procesos o actividades (Barone Eisner, 2006; Sullivan, 2005). Según Roldán, no es suficiente tomar fotografías con ciertas cualidades estéticas: la fotografía se convierte en un método de investigación cuando es una parte sustancial y sistemática del proceso de investigación en sí; en consecuencia, se convierte en un resultado de búsqueda cuando logra resolver un problema que, de alguna manera, puede ser reconocido o compartido por otras personas.

\subsection{Diseño y fotografía al servicio de la investigación: San Gennaro Vesuviano}

Para el máster de nivel II en Arte y Educación de la Universidad de Granada en 2017, la autora realizó una investigación de un año en el jardín de infantes público de San Gennaro Vesuviano, que tituló Juego de roles. El juego y los roles en el proceso de aprendizaje de los niños de edad preescolar en la escuela de San Gennaro Vesuviano en Italia: un estudio basado en Artes Visuales.

De acuerdo con los principios de la Investigación Educativa basada en Artes Visuales, la autora ha utilizado las imágenes producidas considerándolas como parte de un discurso en el que la presentación del tema es necesaria para su descripción e interpretación de las diferentes fases y situaciones experimentadas. En las fotografías, la autora ha capturado el momento preciso en que el niño se transforma en otro yo, y ha tratado de resaltar cómo el aspecto lúdico y teatral de los juegos de rol y otras actividades para niños que cumplen las funciones estéticas utilizadas por ellos para mostrar y describir la realidad, proyectar su identidad, definir sus deseos y concretar sus fobias, etc.: todos los aspectos que se prestan a ser visualizados a través de la fotografía, el dibujo y las imágenes igual que los niños. Pero es sobre todo la fotografía la que literalmente nos permite "ver" las representaciones imaginarias producidas por los niños en sus juegos, en otras palabras, visualizar lo que sucede en su mente cuando imaginan. 
Como se anticipó al comienzo de este artículo, en la investigación la autora ha podido verificar cómo las principales referencias de los niños en sus juegos son dibujos animados y cómo la televisión ha entrado de manera tan dominante en su vida diaria hasta el punto de que estos personajes de referencia se convierten en su propia realidad. En el juego, los niños que ha observado y fotografiado ajustan su cultura a la cultura visual, como si la realidad que experimentan todos los días no sea más que la que se ve en sus programas favoritos.
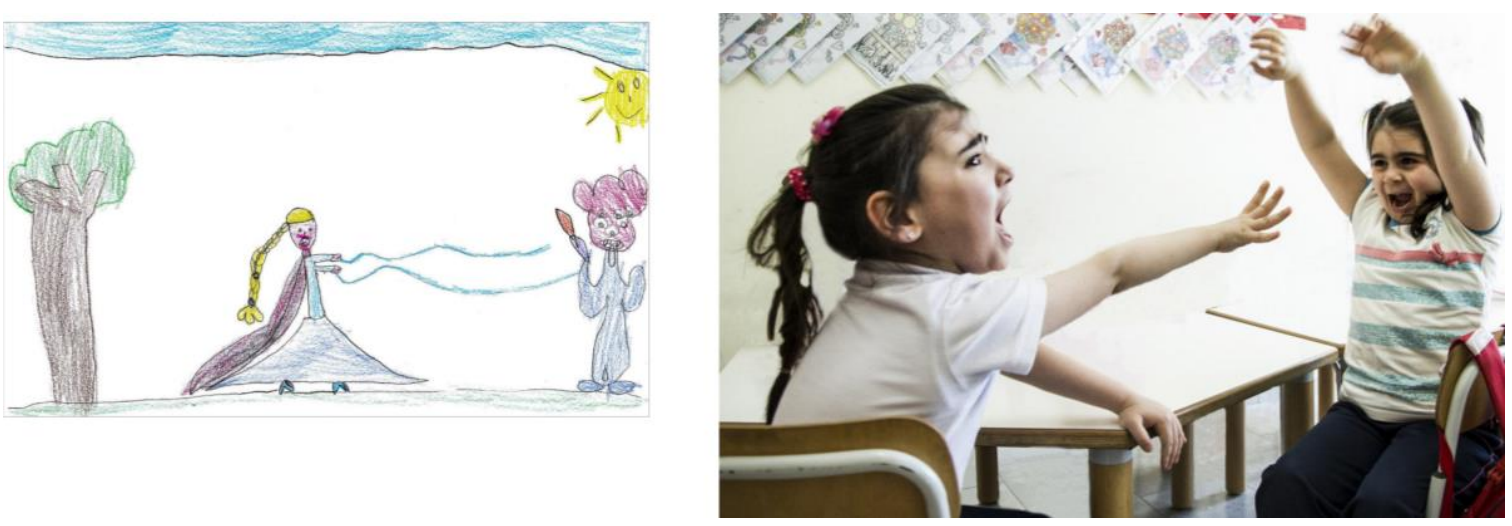

7. Par fotográfico. Autora. (2017). Consta de una fotografía que representa a dos niñas de cinco años que se transforman en los personajes de la película animada "Frozen" y un dibujo que ilustra la caricatura antes mencionadas.

\subsection{Dibujo y fotografía al servicio de la investigación: nuevos caminos}

Después de trabajar alrededor de la imaginación de los niños de una escuela pública, el interés del autor se dirigió a las escuelas con enfoques educativos alternativos, por lo tanto, vinculados a diferentes métodos pedagógicos experimentales, como la escuela activa, el método Reggio Emilia, Steiner o Montessori. El objetivo que me propuse es comprender, a través de una investigación comparativa, cómo los niños y las niñas desarrollan su imaginación con respecto al enfoque educativo diferente adoptado por las escuelas a las que asisten. Hablar de pedagogía alternativa significa referirse a un proceso educativo que facilita el aprendizaje y la enseñanza con el uso de diversas estrategias didácticas adecuadas para la formación de un estilo de acción pedagógica diferente al utilizado en la educación tradicional, que tiene características típicas del formalismo, memorización y repetición.

El estudio tiene como objetivo examinar a los niños en su juego libre y, por lo tanto, la observación de la autora no interferirá de ninguna manera con su juego. No habrá intervenciones o sugerencias para desarrollar un rol, y esto se debe a que, para su desarrollo, el juego debe basarse en la plena libertad y voluntariedad de quienes participan en él. 
ISSN: $2340-9096$

https://dx.doi.org/10.17561/rtc.extra2.5790

El proyecto de investigación se dividirá en varias secciones. La primera fase, de recuperación y análisis de datos, tendrá como objetivo examinar los lugares del juego y el comportamiento de los niños en relación entre sí. En una segunda fase, relacionada con la fotografía, trataré de capturar con la lente el momento en que el niño se convierte en otro personaje; esta fase también estará relacionada con el dibujo, de hecho, les pediré a los niños que dibujen el personaje que eligieron inmediatamente después de jugar, para que el dibujo sea más probable; unos días más tarde tendrá lugar una foto provocación, en la que mostraré la imagen fotográfica tomada durante el juego gratuito para verificar cómo afecta esto a la memoria, cuando se pida que dibuje el papel elegido. La fase final coincidirá con un momento fotográfico que realizarán los propios niños: deberán fotografiar a sus compañeros en el momento de la transformación de roles. 


\section{Referencias}

Acaso, M. (2009), La Educación Artística no son manualidades. Nuevas prácticas en la enseñanza de las artes y la cultura visual, Madrid: La Catarata.

Arboleda Estudillo, R. (2013), Repercusiones del consumo de dibujo animado sobre la creatividad infantil, Granada: Universidad de Granada.

Aznar, F. - Batista, V. - González, L. (2000), "Patrimonio, figuración gráfica infantil y aprendizaje. Relación dinamizada a través del discurso del linguaje visual", in Hernández, M. - Sánchez, M. (eds), Educación artística y arte del linguaje infantil, Madrid: Fundamentos.

Barone, T. - Eisner, E. (2006), Arts-based Educational Research, New York: Sage Publications.

Bruner, J. (1984), Acción, pensamiento y lenguaje, Madrid: Alianza Psicología.

Buckingham, D. (2005), Educación en medios. Alfabetización, aprendizaje y cultura contemporánea, Barcelona: Paidós.

Cabanellas, M. I. (1975), Los orígenes de la imagen plástica: significaciones de la línea y la mancha en la expresión plástica infantil, Madrid: Editorial de la Universidad Complutense.

Callejo, S. (2014), El valor educativo del dibujo infantil como instrumento de diagnóstico escolar, Universidad de Valladolid: Facultad de Educación de Segovia.

Carpenter, D. (2003), “Cartoon Therapy. Not-So-Loony Tunes”, H\&HN (Hospitals \& Health Networks), LXXVII (1), pp. 24-26.

Chacón Gordillo, P. D. (2011), Cultura visual y dibujo infantil, Universidad de Granada: Ikasart.

Delval, J. (1995), El desarrollo humano, Madrid: Siglo XXI de España Editores.

González Hernando, E. (2015), Dibujo infantil como medio de diagnóstico, Universidad de Valladolid. 
Lotman, J. M. (1973), "Il problema del segno e del sistema segnico nella tipologia della cultura russa prima del XX secolo", in Lotman, J. M. - Uspenskij, B. A. Uspenskij (eds), Ricerche semiotiche, Torino: Einaudi.

Maestre, A. B. (2010), "El dibujo en la escuela", Innovación y experiencias educativas, XXVI. Recuperado de http://www.csicsif.es/andalucia/modules/mod ense/revista/pdf/Numero 26/ANA BEL EN_MAESTRE_CASTRO_01.pdf

Perner, J. (1994), Comprender la mente representacional, Barcelona: Paidós.

Roldán, J. (2012), Metodologías artísticas de investigación en educación, Málaga: Ediciones Aljibe.

Sáinz, A. (2003), El arte infantil, Madrid: Eneida.

Steinberg, R. - Kincheloe, J. L. (2000), Cultura infantil y multinacionales, Madrid: Morata.

Sullivan, G. (2005), Art Practice as Research: Inquiry in the Visual Arts, Thousand Oaks, CA: Sage Publications.

Tappolet, U. (1982), Las marionetas en la educación: la muñeca de la nariz menuda, Barcelona: Editorial Científica-médica.

Tejerina Lobo, I. (2005), El juego dramático en la educación primaria, Escuela Universitaria de Magisterio de la Universidad de Cantabria: Biblioteca Virtual Miguel de Cervantes. 
UNED (2015), El desarrollo de la capacidad de representación. Recuperado de http://www.psicocode.com/resumenes/5desarrollo.pdf.

Vandenplas - Holper, C. (1982), Educación y desarrollo social del alumno, Madrid: Anaya.

Vygotskij, L. S. (1979), El desarrollo de los procesos psicológicos superiores, Barcelona: Crítica.

Vygotskij, L. S. (1986), La imaginación y el arte en la infancia, Madrid: Akal.

Wallach, M. A. - Kogan, N. (1983), “Creatividad e inteligencia en el niño”, in Strom, R. D. (ed), Creatividad y educación, Barcelona: Paidós.

Weber, S. - Mitchell, C. (2004), Visual Artistic Modes of Representation for Self-Study, Dordrecht: Springer.

Winnicott, D. W. (1982), Realidad y juego, Barcelona: Gedisa. 
Revista de Estudios en Sociedad, Artes y Gestión Cultural

ISSN: 2340-9096

https://dx.doi.org/10.17561/rtc.extra2.5790
Monográfico

174

traordinario II

Octubre 2020

Investigación 